\title{
A model for integrating work safety into the design of technical equipments
}

\author{
Roland Iosif Moraru, ${ }^{1, *}$, Gabriel Bujor - Băbuţ ${ }^{1}$, Mihai Popescu - Stelea ${ }^{1}$, and Marius \\ Simion Morar ${ }^{3}$ \\ ${ }^{1}$ University of Petroşani, Faculty of Mines, 332006 Petroşani, Romania \\ ${ }^{3}$ National Institute for Research and Development in Mine Safety and Protection to Explosion - \\ INSEMEX Petroșani, 332047, Petroșani, Hunedoara County, Romania
}

\begin{abstract}
The paper proposes a model unfolded for occupational safety aspects inclusion in the design and management of change stages for a piece of machinery. The "Integrated Safety - Technical Equipment" (ISTE) model substantiates a logical connection between various taskbased features to be fulfilled, hazardous areas and occurrences, hazards, risk assessment, ways to wedge in, workplace characteristics, the effect of the working environment, work crew as well as apparatus, tools and/or basically corresponding to and following a set of prior theoretically grounded guidelines, found in literature. At the same time, the paper gives the outline of the case study performed to give proof of the practical model's, illustrating operational safety design for a mechanical press line, used for sheet metal milling. Resorting to the developed model, it was performed the design, construction and assembling of the automatic press line which is compliant in terms of occupational safety.
\end{abstract}

\section{Introduction}

The massive introduction of new technologies into the design and production of manufacturing equipment, through the widespread use of automation and IT technology, has led to increased performance of technical equipment in terms of quality, productivity, flexibility and availability. However, a number of difficulties remain, which generally refer to:

i. the execution phases of these systems, particularly in the assembly, maintenance, postaccident interventions, as well as spare parts provision and safe operation;

ii. the design phase of the technical equipment, because it is very difficult for the designer to consider all the factors that concern the health and safety at work and the integration of all activities and operator's interventions.

Often, the analysis of these situations highlights the large differences between the performances projected in the design phase of technical equipment and those observed in operation, including manufacturing constraints, prolonging the life of technical equipment, process variability, etc. This shortcoming is considered to be the main cause not only for

* Corresponding author: roland_moraru@yahoo.com 
poor performance but also for the risk assumed by operators as they are confronted with situations that have not been taken into account during the design phase [1].

Therefore, consideration of safety and human factors in the design phase is essential if the expected performance is to be found in materialized results in the form of any machinery. Although many researchers have approached a very wide range of issues, there are not many who have been concerned with addressing occupational health and safety issues at the design stage of technical equipment [2-3]. However, there are many papers that reviewed or analyzed various methods, means and approaches to integrate safety into design, or offered new research or design methods [4-5]. Conceptualizing a model for addressing safety and health at work in the design phase of the machine has been developed from simple products. However, if the product is a complex production system, the modeling must be based on the needs of human intervention and risk assessment [6-7].

\section{Intrinsic prevention features}

During the process of designing technical equipment, researchers and designers are confronted with several issues, of which the most important are:

i. lack of adequate data on new innovations or patterns created by the project;

ii. the inability to predict the different needs of human intervention as well as the risks associated with each activity;

iii. identifying the correct use and misuse of the equipment by the user as well as the accuracy of maintenance and fault detection activities;

iv. considering several types of specialized knowledge that lead to the decision making on the analyzed problems as well as the realization of the interdependence between the complex knowledge;

v. establishing links between different disciplines, driven by mechanical, electrical and command systems that can lead to conflicts to be mastered.

Integration of work safety into conception/design stage is a necessity both for improving the technical performance in terms of normal or defective operation or maintenance, as well as for adjustments, troubleshooting, production changes etc. This integration requires tools and methods to facilitate communication between different specializations involved in the design process. The lack of means and methods, ascertained by the results of the analyzes carried out, led to the elaboration of models related to the design of the production systems, which take into account the risks that may arise during the exploitation phase.

Designing a machine from the point of view of work safety requires a complex set of concrete actions that include the study of the machine throughout its lifetime and the development of instructions on all the life phases of the machine [8], [9].The study of the technical equipment during its lifetime presupposes:

i. preparing the execution documentation, finding technical solutions, making calculations, choosing the materials, establishing the manufacturing technologies, drawing up the execution plans;

ii. effective completion of the technical equipment in the manufacturing process;

iii. transport and commissioning (installation, testing);

iv. use of equipment requiring adjustment, training / programming or change of manufacturing, operation, cleaning, fault detection and maintenance;

v. dismantling and, to the extent that safety is involved, cessation.

Two categories of safety features are recognized:

a) Direct safety functions are functions whose unrealisation / alteration leads instantly to an increased risk of injury. In turn they can be: 
- actual safety features, these being direct functions specifically designed to ensure safety. A good example of such a function is that which prevents the unexpected start of a machine (any starting that generates a risk due to its unexpected nature);

- safety features other than the actual ones, for example adjusting the speed or temperature required to keep the machine within safety limits.

b) Indirect safety functions are functions whose failure / alteration does not instantly generate a hazard but diminishes the safety level. They usually consist of automatically supervising all direct safety features.

By automatic surveillance, it is permissible to initiate the safety measure when the ability of a component to perform its function is reduced or the operational conditions change, generating hazards. Automatic supervision may be "continuous" when a safety measure is initiated immediately after a fault occurs, and "discontinuous" when a safety barrier is initiated after the failure occurs.

\section{The "Integrated Safety - Technical Equipment" model}

Figure 1 presents the model developed to include occupational safety issues in the design of the technical equipment. The model includes a logical linking between a variety of features related to tasks to be solved, hazardous areas and events, hazards, risk assessment, ways to intervene, workplace, environmental influences, working team as well as tools and consumables used. All these aspects are set up in the context of the harmonized EU standards, as well as the normative acts transposing them into the national legislation [10$11]$.

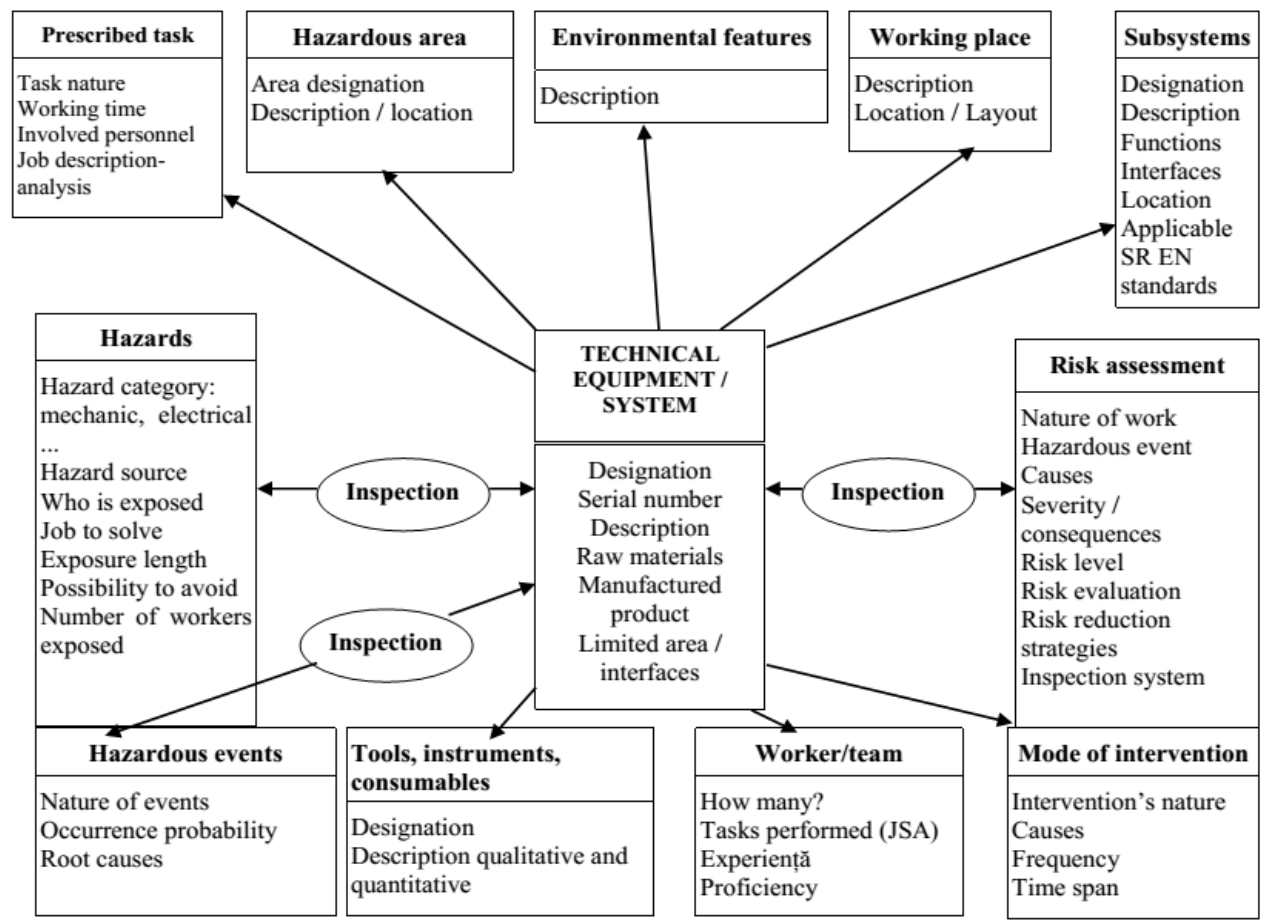

Fig. 1. The "Integrated Safety - Technical Equipment" model 
The features of the model are detailed below.

i. Technical equipment / system: it includes the name of the equipment, the serial number of the production; the description of the equipment, the raw material processed, the finished product resulting from the use of the equipment. It is important to identify equipment boundaries and interfaces with other systems.

ii. Subsystem: This component identifies the components of the equipment and includes their name, description, operation, and location. It is important that in this description are identified for each equipment the relevant EU directives as well as the applicable harmonized EN standards.

iii. Intervention mode: represents the interactions between the equipment and the user, ie, the means by which access to hazardous areas is allowed to perform planned activities (tool change, maintenance, defect detection, programming, etc). In addition to the causes for which the human operator has to enter the hazardous area, the frequency of interventions and their duration should be specified.

iv. Work team: includes all workers who carry out installation, operation, adjustment, adjustment, replacement, cleaning, maintenance and repair of the machine.

v. Hazardous area: is any area, inside and / or outside of an equipment in which a person is exposed to hazard.

vi. Hazardous event: is one of the events that may or may not happen during the work and which is caused by users, work systems or a third party.

vii. Tools and consumables.

viii. Workplace: Detailed job description and location.

ix. Working environment: encompasses all the physical, chemical, biological, management, social, and cultural elements that surround a working situation existing in a work area.

According to the proposed model, a specific risk assessment procedure has been devised, which essentially corresponds to and follows the theoretically grounded guidelines in literature [12-16].The theoretical considerations and the experience gained from practical work, aspects that are more or less emphasized in the literature, led to the promotion of two basic risk assessment techniques, which are considered to be most relevant to machine safety. These techniques relate to: i) the hazard - based approach;ii) the task - based approach. The task-based risk assessment is much more open than the analysis of the various hazards associated with each step of the working task.

\section{Case study}

The case study used to demonstrate the application of the developed model is based on the design of a 1200/800 tonne mechanical press line used for metal sheet stamping. The 5 mechanical presses, considered in the context of a technological line and not individually, do not meet the EU's machine safety requirements. By applying the model, designing in order to construct and assemble an automatic line that corresponds from the point of view of the safety of work, has been pursued.

The technological line comprises (figure 2), besides five simple-action presses, two trolleys with crane, one take-off mass, seven six-degree robots, one central transfer table for tilting, one conveyor and ten molds. The meaning of the notations is as follows:

01 - trolleys with crane for table handling, loading on the trolley and unloading on the pickup table;

02 - pick-up table;

03 - six-degree robots for picking up metal sheets from the table and arranging them on the first press to perform the first operation, as well as passing them on the other presses for the following operations; 
04 - presses;

05 - molds that are mounted on presses for profile shaping;

06 - spaces on press (picking up and spreading to other presses or carriers);

07 - conveyor for evacuating plates from the manufacturing line.

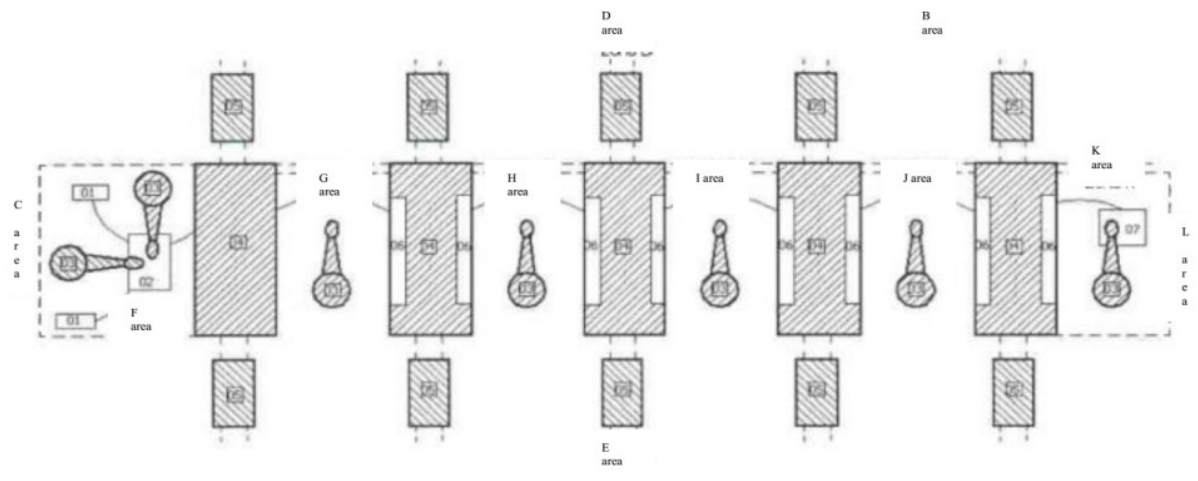

Fig. 2. General layout of the manufacturing line

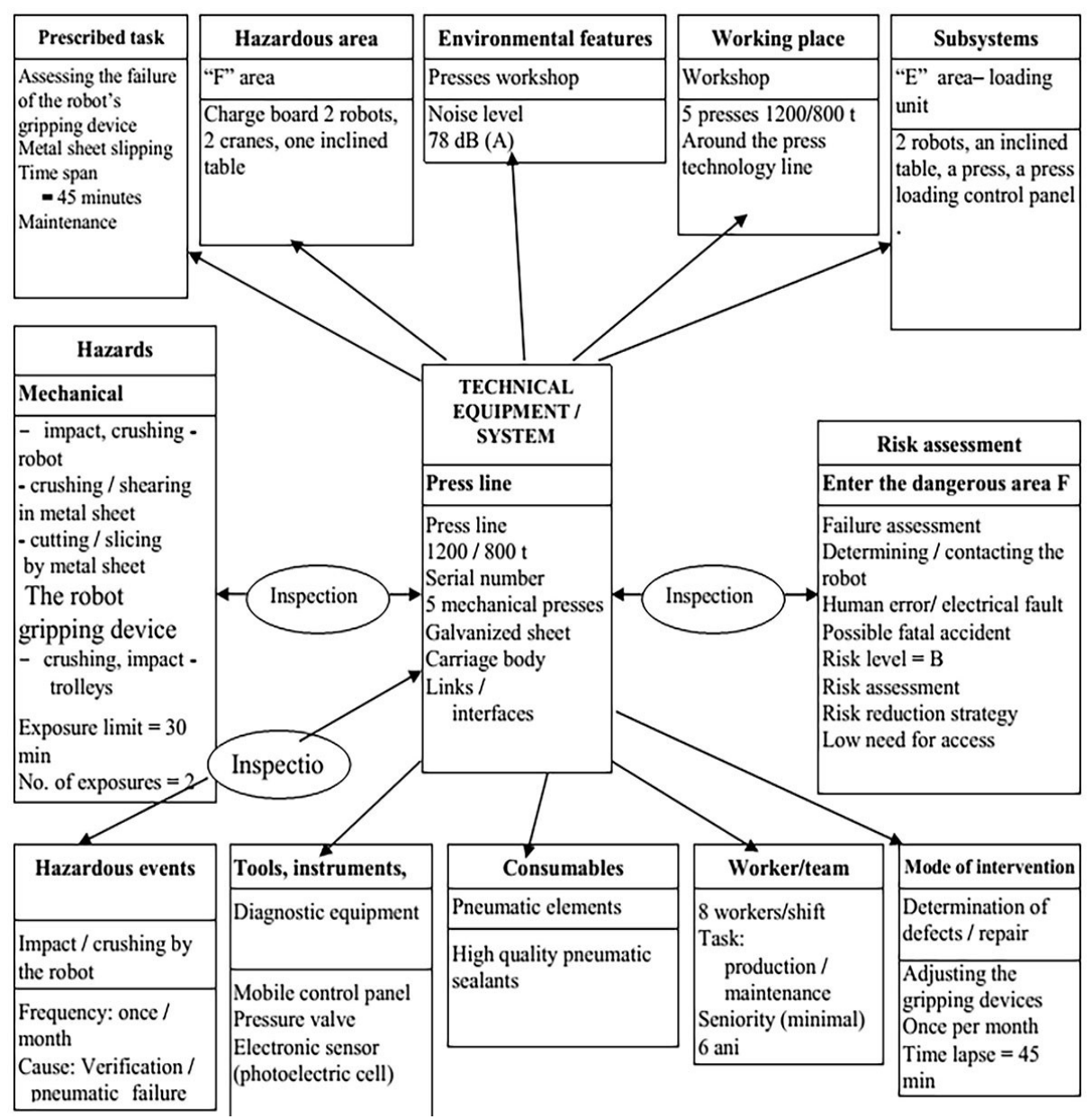

Fig. 3. Application of the model to a press line 
Figure 3 shows the application of the model to an intervention situation related to the handling of the metal sheet inside the hazardous area $\mathrm{F}$ due to a failure of the robot, of the control of the sheet gripping and handling element or the failure of the pneumatic drive system. The company works in the three-shift system, each of which consists of eight people per shift. Maintenance activity is included as part of the production program, applying the flexible system, depending on the specialization of the workers. The work line starts by loading the tables on trolleys with crane, mark 01 , in area $\mathrm{C}$. The load moves automatically to area F, where a robot, mark 03 , at set intervals, sorts a metal sheet and places it on the center table, mark 02. A second robot picks up the sheet and places it between the molds of the first mechanical press. Between the presses there is a robot to maneuver the semi-profiled sheets until the final shape is obtained, which is taken over by a conveyor 07.

A task-based approach to risk assessment was used to assess the risks for the two maintenance teams involved in defining the fault. As a result of the risk assessment, an attempt was made to reduce the need for access in zone f as well as zones $g, h, i, j$ and $k$ for defect detection when the robot is under load.

Then, there has been made a change in design by which the robot's gripping element can be changed automatically without needing to enter the hazardous area. This concept is shown in Figure 4.

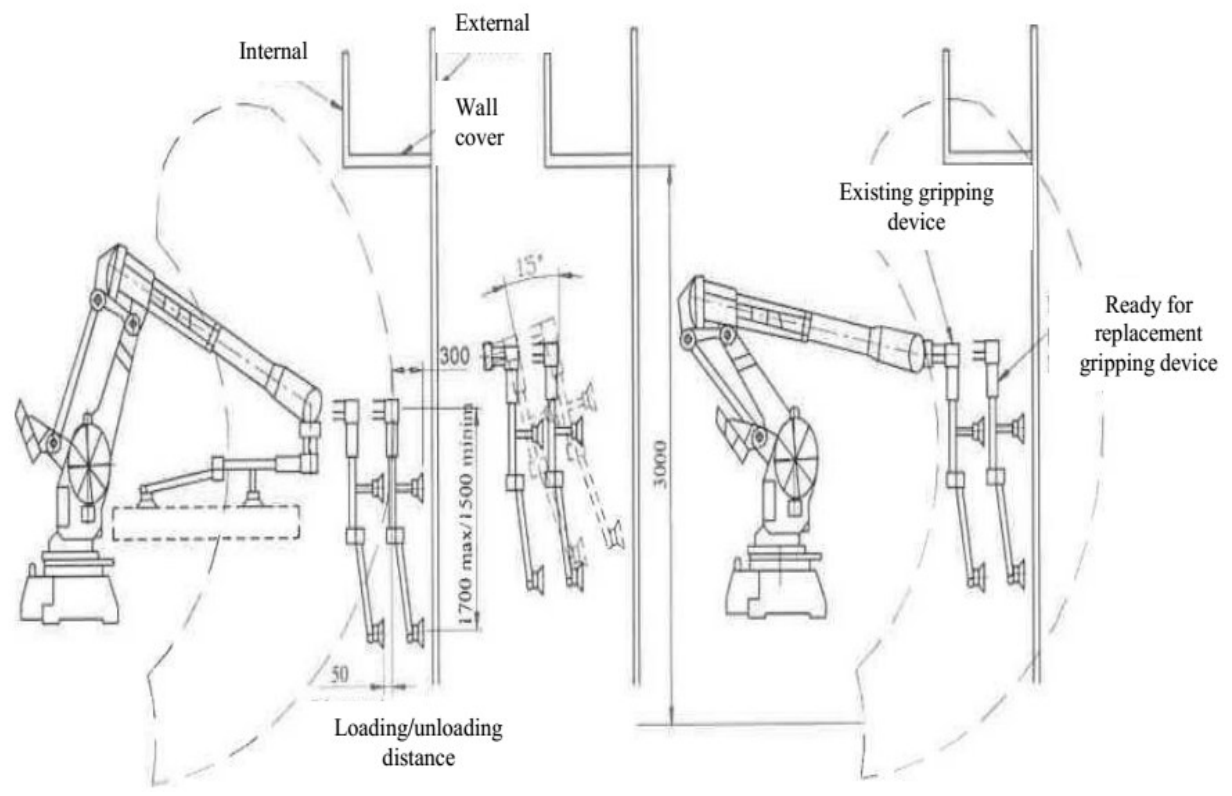

Fig. 4. Automatically change of the robot's gripping device

Another safety measure resulting from the risk assessment included the introduction of diagnostic systems. Figure 5 shows all the improvements in the press line safety system as a result of the application of the model. The main protection system is a combination of locking devices and photoelectric components. 


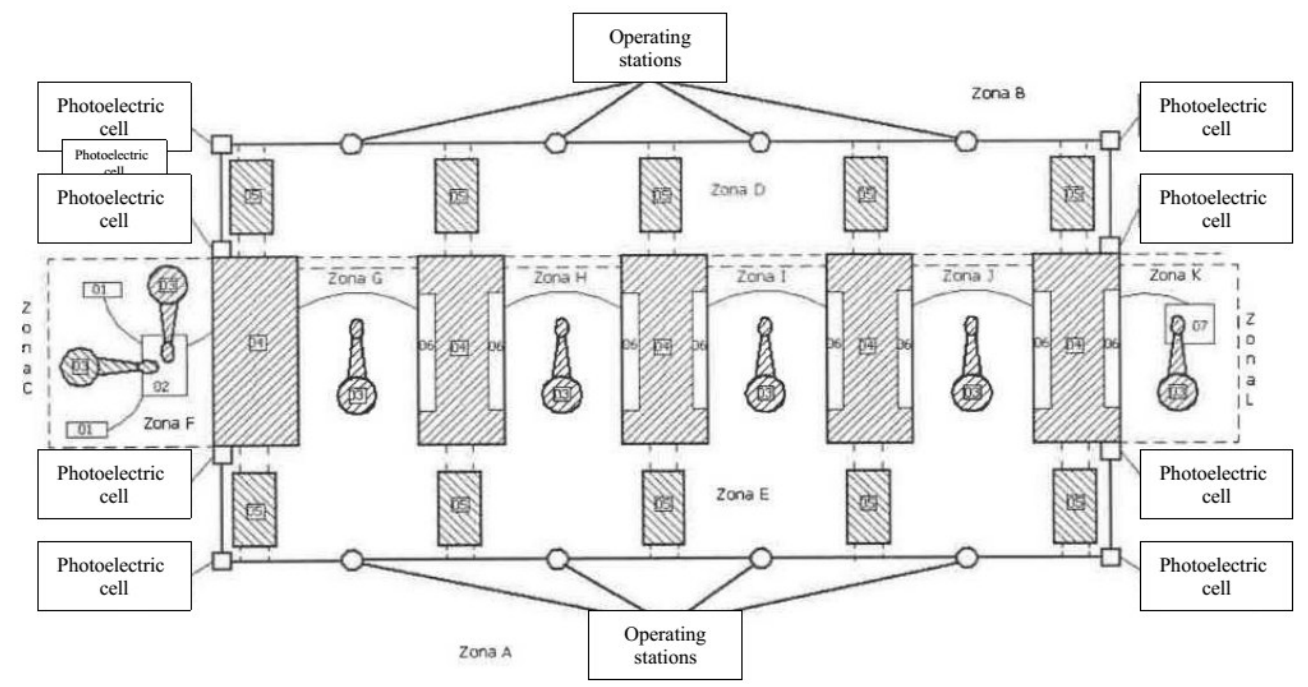

Fig. 5. Layout of safety systems

\section{Conclusions}

In order to ensure the safety of the technical equipment at the design stage, it is necessary to comply to a series of principles and related techniques, which have been hierarchized and briefly systematized in the paper.

The interogation "Is safety appropriate?" means answering the questions below:

- the proposed safety level has been reached?

- is there a certainty that an equivalent safety level can not be achieved more easily?

- is there a certainty that the measures taken do not excessively reduce the machine's ability to perform its function and do not generate new unforeseen threats?

- are there solutions for all conditions of use and for all intervention procedures?

- are the solutions compatible?

- aren't the operator's working conditions compromised by these solutions?

Intrinsic prevention consists of applying, separately or together, measures to minimize hazards by choosing the appropriate features of the press and limiting people's exposure to hazards by reducing the need for operator intervention in hazardous areas.

Means of protection are applied to protect people from the dangers that can not be avoided / limited / minimized by effective preventive measures.

The rules on the means of protection refer to the selection and the requirements to be satisfied when designing and constructing protective and protective devices. Information for use must treat, separately or in combination, transport, commissioning (assembling, installation, testing), use (adjustment, training, programming, manufacturing change, operation, cleaning, fault finding and maintenance) and whether it is necessary, decommissioning and scrapping. The specific security measures resulting from the risk assessment and the application of the developed model include:

- changing all five presses taking into account current European regulations;

- creating and improving safety curtains around L and F zones and between presses.

Curtains are fitted with control systems according to current European standards;

- design and location of photoelectric cell devices. 
It is recalled that not all risk requires reduction measures. This is necessary when the level of risk is significant, so the designer should propose a hierarchy of risk mitigation options.

\section{References}

1. R.I., Moraru, L.I., Cioca, Operational safety measures in human-machine systems: an overview, Proceedings of the $18^{\text {th }}$ International Conference - The Knowledge-Based Organization: Management and Military Sciences - KBO 2012, pp. 86-91, Sibiu, Romania (2012)

2. G.B., Băbuţ, R.I., Moraru, General principles and framework of machinery risk management, ,, Quality Access to Success" Journal, Volume 18, Supplement 1, pp. 19-24 (2017)

3. L.I., Cioca, R.I., Moraru, G.B., Băbuţ, A Framework for Organisational Characteristic Assessment and their Influences on Safety and Health at Work, Proceedings of the $15^{\text {th }}$ International Scientific Conference „The Knowledge Based Organization”, vol. 2, section: Management, pp. 43-48, Land Forces Academy Sibiu, Romania (2009)

4. L. Ivaşcu, L.I., Cioca, Opportunity Risk: Integrated Approach to Risk Management for Creating Enterprise Opportunities, The $2^{\text {nd }}$ International Conference on Psychology, Management and Social Science, Psychology, Management and Social Science, Shenzhen, China, Book Series: Advances in Education Research, Volume 49, pp.77-80 (2014)

5. G.B., Băbuţ, R.I., Moraru, M., Popescu-Stelea, Critical analysis and ways to improve the terminology employed in the machinery safety field, Quality - Access to Success Journal, Volume 16, Issue 149, pp. 98-106 (2015)

6. R.I., Moraru, G.B., Băbuţ, L.I., Cioca, Knowledge Based Hazard Analysis Guidelines for Operational Transportation Projects, Proceedings of the 15th International Conference the Knowledge Based Organization: Management, Volume 2, pp. 117-122, Sibiu, Romania (2009)

7. R.I., Moraru, G.B., Băbuţ, L.I., Cioca, Knowledge management applications in occupational risk assessment processes, Proceedings of the $17^{\text {th }}$ International Conference - The Knowledge-Based Organization: Management and Military Sciences, pp. 735-740, Sibiu, Romania (2011)

8. ASRO, SR EN ISO 12100: 2011 - Safety of machinery. General principles for design. Risk assessment and risk reduction (in Romanian), Romanian Standards Association (ASRO), Bucharest, Romania (2011)

9. Romanian Government, Government Decision no. 1146/2006 concerning the minimum safety and health requirements for the use of work equipment by workers at work (in Romanian), The Official Journal of Romania, Part I, no. 815/03.10.2006 (2006)

10. Romanian Government, Government Decision no. 1029/2008 regarding the conditions for placing machines on the market (in Romanian), The Official Journal of Romania, Part I, no. 674/30.09.2008 (2008)

11. Romanian Government, Government Decision no. 517/2011 for amending and supplementing Government Decision no. 1029/2008 regarding the conditions for placing machines on the market (in Romanian), The Official Journal of Romania, Part I, no. 373/27.05.2011 (2011)

12. Moraru, R.I., Băbuţ, G.B., Principles and guidelines regarding the risk management implementation: The new ISO 31000:2009 standard, Quality - Access to Success Journal, 11, Issue 4, pp. 50-59 (2010)

13. R.I., Moraru, G.B, Băbuţ, L.I., Cioca, Drawbacks and traps in risk assessment: examples in Romania, Proceedings of the 5th International Conference on Manufacturing Science and Educations - MSE 2011, Volume 2, pp. 363-366, Sibiu, Romania (2011)

14. Ivascu, L., Cirjaliu, B., Draghici, A., Business model for the university-industry collaboration in open innovation, 3rd Global Conference on Business, Economics, Management and Tourism (BEMTUR), vol. 39, pp. 674-678, Roma, Italia (2015)

15. M., Cioca, M., L-I., Cioca, Multi-criterion analysis of reference architectures and modeling languages used in production systems modeling, $3^{\text {rd }}$ IEEE International Conference on Industrial Informatics, INDIN, 1560381, pp. 230-233 (2005)

16. D.-C., Darabont, C., Bejinariu, C., Baciu, M.-A., Bernevig-Sava, Modern approaches in integrated management systems of quality, environmental and occupational health and safety, Quality - Acces to Succes 20, pp. 105-108 (2017) 